\title{
PERANCANGAN IDENTITAS VISUAL UNTUK PROMOSI PARIWISATA KABUPATEN REMBANG
}

\author{
Renta Yusantiar ${ }^{1}$, Didit Widiatmoko Soewardikoen ${ }^{2}$ \\ 1,2Prodi Desain Komunikasi Visual, Fakultas Industri Kreatif, Universitas Telkom \\ rentayusantiar@gmail.com ${ }^{1}$, widiatmokodw@gmail.com ${ }^{2}$
}

\begin{abstract}
Abstrak
Kabupaten Rembang sedang mengembangkan pariwisata yang dimilikinya. Upaya berpromosi telah dilakukan oleh berbagai pihak, baik pihak pemerintah kabupaten Rembang, pegelola, hingga masyarakat. Namun, identitas visual yang telah digunakan belum memiliki keseragaman yang baik dalam penggunaan warna dan tipografi. identitas visual dan promosi pariwisata Kabupaten Rembang dalam periode Januari-Juli 2017 menjadi fokus penelitian ini. Penelitian dilakukan di Rembang menggunakan metode observasi, studi pustaka, wawancara dan kuesioner serta analisis dilakukan dengan matriks perbandingan. Tujuan penelitian adalah meningkatkan kesadaran masyarakat terhadap potensi wisata yang dimiliki Kabupaten Rembang. Hasil yang diperoleh dari penelitian ini bahwa kabupaten Rembang dan potensi wisata yang ada memerlukan pembakuan identitas visual dan penerapannya pada media promosi yang sesuai agar dikenal masyarakat luas dan akan berdampak pada peningkatan pendapatan daerah serta masyarakat Kabupaten Rembang.
\end{abstract}

Kata kunci : wisata, Rembang, identitas visual, promosi

\begin{abstract}
Rembang Regency is developing its tourism. Promotion efforts have been made by various parties, both the district government of Rembang, the manager, until the community. However, the visual identity that has been used has not had a good uniformity in the use of color and typography. Visual identity and tourism promotion of Rembang Regency in the period from January to July 2017 become the focus of this research. The research was conducted in Rembang using observation method, literature study, interview and questionnaire and analysis was done with comparison matrix. The objective of the research is to increase public awareness of tourism potential owned by Rembang Regency. The results obtained from this study that Rembang district and the potential of existing tourism requires the visual identity recognition and its application to the appropriate promotional media to be known to the wider community and will have an impact on the increase of regional income and the community of Rembang Regency.
\end{abstract}

Keywords: tourism, Rembang, visual identity, promotion 


\section{PENDAHULUAN}

Indonesia memiliki aneka ragam potensi wisata yang menjadi nilai tambah di mata dunia. Hal tersebut ditandai dengan meningkatnya kunjungan wisatawan mancanegara di Indonesia pada tahun 2016 dibandingkan dengan tahun 2015. Pesona Indonesia menjadi salah satu upaya dari Kementerian Pariwisata untuk mempromosikan wisata Indonesia. Selain program pemerintah, pengguna media sosial pun ikut serta dalam mempromosikan potensi wisata Indonesia melalui akun-akun yang memberikan informasi terkait lokasi wisata. Upaya dalam mempromosikan potensi wisata di Indonesia, berdampak positif dengan mulai dikenalnya objek wisata di berbagai daerah. Meskipun demikian, masih terdapat berbagai tempat yang masih asing di telinga wisatawan, seperti wisata di Kabupaten Rembang.

Letak kabupaten Rembang di Pesisir Utara Pulau Jawa dan berbatasan langsung dengan provinsi Jawa Timur yang berada di tepi laut, membuat kabupaten Rembang memiliki berbagai pantai yang dimanfaatkan untuk kegiatan wisata. Selain pantai, kabupaten Rembang sendiri memiliki berbagai potensi wisata alam, sejarah dan budaya, serta kuliner. Dengan adanya potensi wisata yang dapat dikembangkan, penelitian ini bertujuan untuk mempromosikan wisata yang dimiliki Kabupaten Rembang agar dapat dikenal oleh masyarakat luas. Selama ini media promosi yang digunakan adalah brosur dan guide book yang hanya dapat diperoleh di kantor Dinas Pariwisata Kabupaten Rembang. Tidak adanya keseragaman dalam desain identitas maupun media promosi yang sudah ada, sehingga upaya promosi yang dilakukan masih belum maksimal.
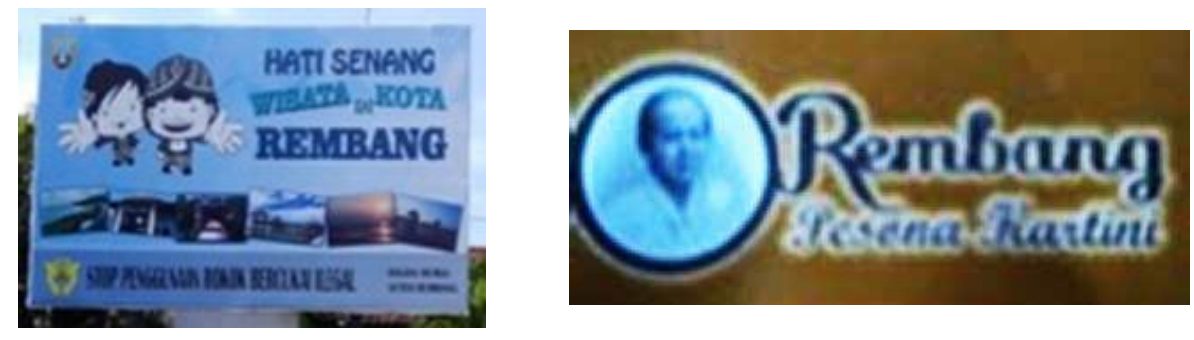

Gambar 1. Desain Identitas dan Media Promosi yang Digunakan

[Sumber: Yusantiar 2017:106]

Wisata Kabupaten Rembang perlu adanya upaya perancangan ulang logo serta promosi untuk dapat meningkatkan minat serta jumlah kunjungan di wisata Kabupaten Rembang. Dengan meningkatnya jumlah kunjungan nantinya akan terjadi peningkatan pendapatan masyarakan serta pemerintah Kabupaten Rembang.

Brand atau merek merupakan sesuatu yang digunakan untuk membedakan produk atau jasa dengan produk atau jasa sejenis dengan fungsi pemenuhan kebutuhan yang sama. Selain pengertiannya, brand juga memiliki kriteria-kriteria yang harus dipenuhi. Seperti yang dijelaskan oleh (Swasty, 2016:32), sebuah brand harus bersifat mengesankan, bermakna, menyenangkan, dapat dialihkan, dapat menyesuaikan diri, dan terlindungi. Sebuah brand membutuhkan sebuah logo yang dibuat dari hasil 
penafsiran sebuah perusahaan ke dalam simbol sebagai tanda pengenal bagi perusahaan di mata pelanggan seperti yang dijelaskan dalam (Wibowo, 2013;258). Selain logo juga terdapat tagline atau slogan yang merupakan kata-kata pendek yang dipilih oleh sebuah merek untuk memberikan pengertian kepada konsumen tentang merek serta produknya, membedakan dengan pesaing serta menjadi pengingat bagi konsumen (Soewardikoen, 2015: 121). Melalui brand wsata Kabupaten Rembang yang baik diharapkan lebih dikenal dan tertanam di benak masyarakat. Brand yang berupa logo dan slogan ini selanjutnya menjadi dasar perancangan media promosi wisata Kabupaten Rembang yang sistematis.

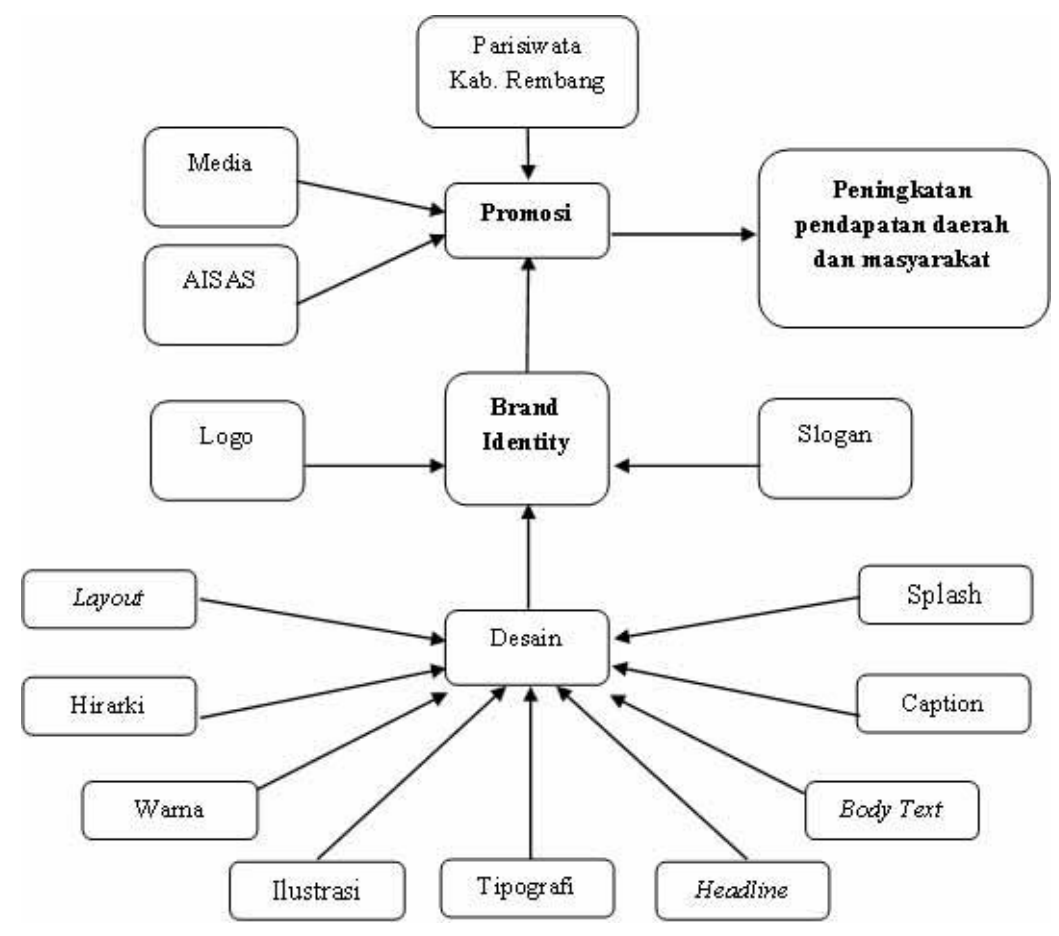

Gambar 2. Kerangka Teoretik

[Sumber: Yusantiar 2017:30]

Promosi merupakan rangkaian usaha dari pemilik brand atau merek untuk menginformasikan mengenai produk atau jasa yang dimilliki kepada target pasar serta mengajak orang untuk menggunakan barang jasa yang ditawarkannya (Morrisan, 2010:16). Dalam promosi, terdapat media-media yang dapat digunakan diantaranya media cetak konvensional (leaflet, flyer, brosur, booklet, co-card, stiker), media luar ruangan (poster, spanduk, billboard, banner, umbul-umbul), media online (website, media sosial, web banner), dan merchandise seperti yang dijelaskan dalam buku Merancang Media Promosi Unik dan Menarik (Ardhi, 2013:14). Melalui promosi wisata Kabupaten Rembang yang gencar dan sistematis berdasarkan brand yang dibuat diharapkan dapat meningkatkan pendapatan daerah dan masyarakat.

Desain sebagai dasar perancangan brand dan promosi yang baik memiliki berbagai unsur seperti tata letak atau layout yang merupakan penonjolan sebuah isi seperti ilustrasi atau gambar atau konten yang penting dengan ukuran paling besar maupun 
dikelilingi oleh bidang putih memiliki tujuan untuk menarik perhatian dari audiens pada konten tersebut. (Soewardikoen, 2015:120). Warna adalah alat komunikasi tanpa bahasa dan bahasa untuk menyampaikan ide, gagasan, maupun pesan yang disampaikan. Selain warna, tipografi juga merupakan penciptaan suatu kesan dan kenyamanan membaca bagi audiens dengan cara memilih dan menata huruf yang sesuai pada suatu bidang dalam memilih tipografi yang benar harus memperhatikan keterbacaan, kejelasan, dapat dilihat, serta legibility (Wibowo, 2013;121). Dalam AISAS terdapat proses attention dan interest yang merupakan media pasif karena tidak adanya peran aktif dari audiens, sebaliknya dengan search, action dan share bersifat aktif karena audiens ikut berperan aktif dalam proses promosi (www.dentsu.com).

\section{METODE PENELITIAN}

Objek dalam penelitian ini adalah pariwisata kabupaten Rembang, cakupannya meliputi lokasi objek, fasilitas, kegiatan pengunjung serta obyek wisata pesaing. Pengumpulan data dilakukan di kabupaten Rembang dengan cara observasi dan wawancara, dalam periode waktu Januari-April 2017. Observasi dilakukan dengan mendokumentasikan kondisi objek, sedangkan wawancara dilakukan kepada pengelola tempat wisata, Dinas Pariwisata Kabupaten Rembang dan pengunjung, untuk mengetahui hal-hal yang tidak dapat ditemukan saat observasi seperti jumlah pengunjung, alasan pengunjung, serta hambatan yang ditemui. Penyebaran kuesioner secara acak melalui google form juga dilakukan untuk mengetahui minat wisata audiens, pengetahuan terhadap wisata kabupaten Rembang, serta media promosi yang sesuai untuk target audiens. Selain itu, juga dilakukan studi pustaka untuk memperoleh teori-teori berkaitan dengan Desain Komunikasi Visual yang dapat bermanfaat serta menjadi pedoman dalam melakukan perancangan. Analisis matriks perbandingan terhadap identitas visual obyek wisata pesaing (Banyuwangi, Jepara, dan Yogyakarta) untuk mengetahui bagaimana identitas visual dan upaya promosi yang telah dilakukan obyek wisata pesaing. Analisis SWOT yang digunakan untuk memperoleh konsep pesan yang sesuai untuk mempromosikan wisata Kabupaten Rembang.

\section{HASIL DAN PEMBAHASAN}

Kabupaten Rembang memiliki lebih dari lima belas lokasi wisata yang dikelola oleh berbagai pihak, seperti Dinas Pariwisata, Dinas Kehutanan, Dinas Kelautan serta masyarakat sekitar lokasi wisata. Pilihan wisata yang terdapat di Kabupaten Rembang diantaranya wisata bahari, wisata alam, wisata kuliner, serta wisata sejarah dan budaya. Dari pengelompokannya tersebut wisata bahari terdapat Pantai Karang Jahe, Pantai Wates, Pulau Gedhe, Pantai Caruban. Wisata alam terdapat Pasucen, air terjun kali mancur, Panohan, Watu Congol.

Wisata kuliner Rembang terdapat kelo mrico, lontong tuyuhan, sate serepeh, legen. Untuk oleh oleh Rembang ada sirop kawisto, dumbeg, emping jagung, ikan asin dan terasi. Wisata sejarah, terdapat wisata sejarah Islam di Pasujudan dan Makam Sunan Bonang di Kecamatan Lasem, serta Museum Kartini, Makam Kartini. Selain itu juga terdapat wisata sejarah dan budaya Tionghoa di Lawang Ombo dan berbagai kelenteng 
di Kabupaten Rembang. Wisata budaya terdapat Situs Terjan, Situs Selodiri, Situs Perahu Kuno, dan Sentra Batik Lasem. Sebagian besar lokasi wisata yang terdapat di Kabupaten Rembang dikelola oleh masyarakat sekitar sehingga terjadi peningkatan pendapatan masyarakat dari sektor pariwisata. Wisata alam, bahari dan kuliner lebih di minati daripada wisata sejarah dan budaya. Wisata sejarah sendiri ramai dikunjungi ketika sedang berlangsung acara tahunan seperti peringatan hari Kartini, dan Haul Sunan Bonang. Sedangkan Sentra Batik Lasem kembali berkembang dengan adanya dukungan dari Dinas UMKM. Dalam data kunjungan wisata tahun 2015 pengunjung terbanyak terdapat pada lokasi wisata Pantai Karang Jahe yang mencapai lebih dari tiga ratus juta orang setahun. Hal tersebut diimbangi juga dengan peningkatan fasilitas yang terdapat di lokasi wisata.

\subsection{Analisis Matriks Perbandingan}

Tabel 1. Matriks Perbandingan Logo Pariwisata [Sumber: Yusantiar 2017:107]

\begin{tabular}{|c|c|c|c|c|}
\hline Brand & Yogyakarta & Banyuwangi & Jepara & Rembang \\
\hline Logo & $\begin{array}{l}\text { Menggunakan } \\
\text { jenis logo } \\
\text { logotype. }\end{array}$ & $\begin{array}{l}\text { Menggunakan jenis } \\
\text { logo abstract forms. }\end{array}$ & $\begin{array}{l}\text { Menggunakan jenis } \\
\text { logo abstract forms. }\end{array}$ & $\begin{array}{l}\text { Menggunakan jenis } \\
\text { logo concrete forms }\end{array}$ \\
\hline Slogan & "Jogja Istimewa" & $\begin{array}{l}\text { "Majestic } \\
\text { Banyuwangi" }\end{array}$ & "Visit Jepara" & "Pesona Kartini" \\
\hline Warna & $\begin{array}{l}\text { Menggunakan } \\
\text { warna merah } \\
\text { simbol dari } \\
\text { Keraton } \\
\text { Yogyakarta } \\
\text { bermakna berani, } \\
\text { tegas dan tekad. }\end{array}$ & $\begin{array}{l}\text { Menggunakan } \\
\text { warna hijau, biru, } \\
\text { dan orange. }\end{array}$ & $\begin{array}{l}\text { Dominasi warna biru } \\
\text { melambangkan laut, } \\
\text { konservatif, bersih dan } \\
\text { teratur. Kuning } \\
\text { bermakna harapan. }\end{array}$ & $\begin{array}{l}\text { Logo pariwisata } \\
\text { Rembang hanya } \\
\text { menggunakan dua } \\
\text { warna yaitu hitam dan } \\
\text { putih. }\end{array}$ \\
\hline Tipografi & $\begin{array}{l}\text { Tipografi dari } \\
\text { “Jogja Istimewa" } \\
\text { menggunakan } \\
\text { huruf yang } \\
\text { diadaptasi dari } \\
\text { aksara jawa. }\end{array}$ & $\begin{array}{l}\text { Modifikasi font old } \\
\text { style memiliki } \\
\text { lengkungan besar } \\
\text { pada serif }\end{array}$ & $\begin{array}{l}\text { Logo "Visit Jepara" } \\
\text { menggunakan font } \\
\text { script. }\end{array}$ & $\begin{array}{l}\text { Menggunakan jenis } \\
\text { huruf script yang tebal, } \\
\text { berorientasi pada masa } \\
\text { lampau. }\end{array}$ \\
\hline Ilustrasi & $\begin{array}{l}\text { Pada logo “Jogja } \\
\text { Istimewa" tidak } \\
\text { menggunakan } \\
\text { ilustrasi. }\end{array}$ & $\begin{array}{l}\text { Ilutrasi merupakan } \\
\text { hasil } \\
\text { penyederhanaan } \\
\text { dari tari Gandrung, } \\
\text { gunung, laut dan } \\
\text { matahari. }\end{array}$ & $\begin{array}{l}\text { Ilustrasi dari “Visit } \\
\text { Jepara” adalah ombak } \\
\text { yang terdapat ikan } \\
\text { didalamnya. }\end{array}$ & $\begin{array}{l}\text { Ilustrasi yang terdapat } \\
\text { pada logo adalah foto } \\
\text { dari RA Kartini yang } \\
\text { menyerupai logo jamu }\end{array}$ \\
\hline & \multicolumn{4}{|c|}{$\begin{array}{l}\text { Kesimpulan } \\
\text { Setiap brand ingin menampilkan kelebihan dan ciri khasnya masing-masing } \\
\text { Setiap logo menggunakan tipografi yang mudah dibaca. } \\
\text { Warna dan ilustrasi dari setiap logo mewakili apa yang ingin ditonjolkan. }\end{array}$} \\
\hline
\end{tabular}


Hasil analisis dari matriks di atas adalah identitas visual yang digunakan oleh Kabupaten Rembang dan kota-kota pesaing, Yogyakarta adalah kota yang paling diminati wisatawan dengan berbagai pilihan wisata yang ditawarkan. Dari media dan informasi yang dicantumkan di dalamnya, Yogyakarta memiliki informasi yang lebih lengkap dengan adanya aplikasi yang dimilikinya. Sedangkan dari segi desain, Yogyakarta memiliki tampilan yang menarik dalam setiap desain yang ditampilkannya. Banyuwangi juga memiliki tampilan website yang menarik dan mudah dipahami, Jepara menarik pada desain baliho, sedangkan Kabupaten Rembang harus lebih diperhatikan dalam pembuatan desainnya. Promosi wisata yang dilakukan oleh Kabupaten Rembang masih sangat terbatas pada media cetak konvensional. Sehingga informasi belum tersebar di masyarakat luas, mengingat penempatan media hanya berada di pusat informasi Dinas Pariwisata Kabupaten Rembang.

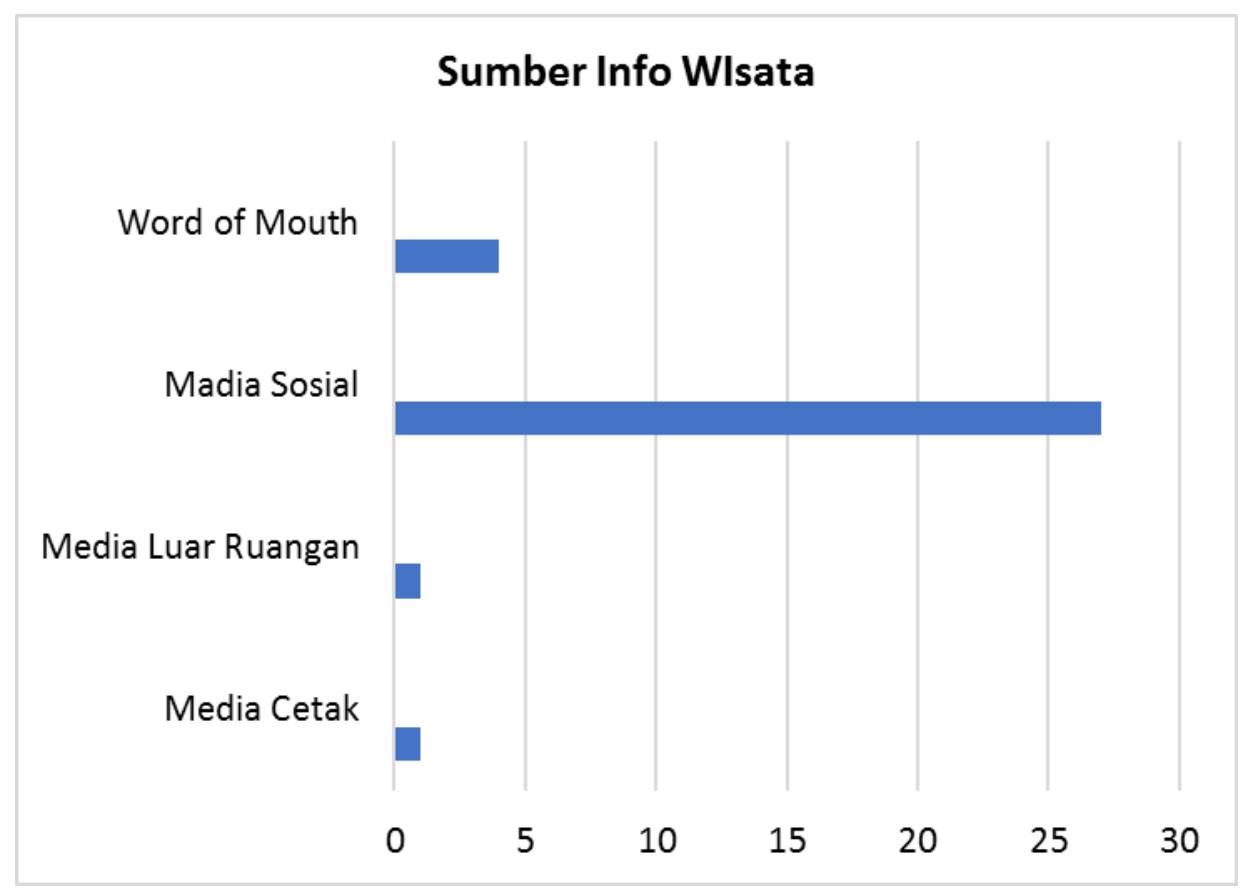

Gambar 3. Data Hasil Kuesioner [Sumber: Yusantiar 2017:104]

Sedangkan dari hasil kuesioner, media sosial atau media online lebih efektif daripada media lainnya. Hal tersebut dikarenakan media online memiliki jangkauan yang lebih luas, serta masyarakat yang sudah banyak beralih pada media ini dalam mencari informasi. 


\subsection{Analisis SWOT}

Tabel 2. Matriks Analisis SWOT untuk Pembetukan Konsep Pesan

[Sumber: Yusantiar 2017:112]

\begin{tabular}{|c|c|c|}
\hline $\begin{array}{l}\text { Analisis } \\
\text { S MOT }\end{array}$ & $\begin{array}{l}\text { Strength } \\
\text { - Lokasi strategis di Jalur } \\
\text { pantura, ombak tenang } \\
\text { dan pantai landai. } \\
\text { - Memiliki hasil laut yang } \\
\text { berlimpah. } \\
\text { - Terdapat wisata bahari, } \\
\text { alam, sejarah, budaya dan } \\
\text { kuliner }\end{array}$ & $\begin{array}{l}\text { Weakness } \\
\text { - Masih terdapat potensi } \\
\text { wisata yang belum } \\
\text { dikelola dengan baik. } \\
\text { - Terbatasnya akomodasi } \\
\text { di lokasi wisata } \\
\text { Kabupaten Rembang. }\end{array}$ \\
\hline $\begin{array}{l}\text { Opportunity } \\
\text { - } \text { Masyarakat mulai } \\
\text { menyukai kegiatan } \\
\text { pariwisata. } \\
\text { - } \text { Dukungan masyarakat } \\
\text { dalam pengembangan } \\
\text { potensi wisata. } \\
\text { - } \text { Perlunya tempat } \\
\text { berkumpul untuk keluarga. }\end{array}$ & $\begin{array}{l}\text { Strength- Opportunity } \\
\text { - Lokasi strategis } \\
\text { - Potensi Wisata } \\
\text { - Hasil laut berlimpah } \\
\text { - Pantai landai, dan ombak } \\
\quad \text { tenang. } \\
\text { - Pengembangan Pariwisata }\end{array}$ & $\begin{array}{l}\text { Weakness- Opportunity } \\
\text { - Pengelolaan yang belum } \\
\text { baik } \\
\text { - Akomodasi terbatas } \\
\text { - Potensi wisata } \\
\text { - Pengembangan } \\
\text { pariwisata }\end{array}$ \\
\hline $\begin{array}{l}\text { Threat } \\
\text { - Banyak wisatawan yang } \\
\text { belum memahami } \\
\text { pentingnya menjaga } \\
\text { kelestarian. } \\
\text { - Wisata didaerah lain sudah } \\
\text { lebih berkembang }\end{array}$ & $\begin{array}{l}\text { Strength- Threat } \\
\text { - Menjaga lingkungan } \\
\text { - Lokasi strategis } \\
\text { - Hasil laut berlimpah } \\
\text { - Kondisi pantai } \\
\text { - Wisata lain sudah } \\
\quad \text { berkembang }\end{array}$ & $\begin{array}{l}\text { Weakness- Threat } \\
\text { - Pengelolaan belum baik } \\
\text { - Akomodasi terbatas } \\
\text { - Menjaga lingkungan } \\
\text { - Wisata lain sudah } \\
\quad \text { berkembang. }\end{array}$ \\
\hline \multicolumn{3}{|c|}{$\begin{array}{l}\text { Konsep pesan dari pilihan Strength- Opportunity : } \\
\text { Lokasi strategis di pantura untuk mengembangkan potensi wisata, pantai yang landai, ombak } \\
\text { yang tenang, dengan memanfaatkan hasil laut berlimpah, cocok untuk wisata keluarga }\end{array}$} \\
\hline
\end{tabular}

Analisis SWOT, dipilih strategi S-O, yaitu Kabupaten Rembang memiliki strength : Lokasi yang strategis karena dilalui Jalur Pantura; Memiliki hasil laut yang berlimpah; Kondisi perairan yang tenang dan landau; Terdapat wisata bahari, alam, sejarah, budaya dan kuliner. Opportunity : Masyarakat mulai menyukai kegiatan pariwisata; Potensi wisata Kabupaten Rembang mulai dikenal oleh masyarakat daerah sekitar Rembang; Adanya dukungan dari masyarakat dalam pengembangan potensi wisata; Perlunya tempat berkumpul untuk keluarga. Strategi S-O ; "Kabupaten Rembang sebagai wisata yang cocok untuk keluarga yang ingin menikmati suasana pantai dan keasrian alam, belajar tentang budaya dan sejarah serta menikmati kuliner khas Kabupaten Rembang dengan harga yang terjangkau." 


\subsection{Konsep Perancangan}

Konsep pesan atau ide pokok perancangan. Kabupaten Rembang merupakan salah satu daerah yang berbatasan langsung dengan Laut Jawa. Hal tersebut menyebabkan kabupaten Rembang memiliki banyak pantai yang landai dan ombak yang tenang. Selain pantai, kabupaten Rembang juga memiliki wisata alam, budaya, sejarah dan kuliner. Berdasarkan data yang telah dikumpulkan, wisata pantai merupakan wisata yang paling diminati di kabupaten Rembang, karena aman untuk semua umur. Pantai di kabupaten Rembang banyak dikunjungi oleh keluarga untuk bermain maupun bersantai bersama. Dari hasil analisis data maka dibentuklah ide pokok perancangan yaitu "Mengajak masyarakat ke Kabupaten Rembang untuk berlibur bersama keluarga."

Dalam proses ide untuk perancangan logo, ilustrasi yang digunakan adalah ikan Manyung dan motif Batik Lasem Sekar Jagad yang akan dipadukan. Pemilihan ikan manyung dan motif Batik Lasem Sekar Jagad tersebut dipilih karena keduanya dapat mewakili Kabupaten Rembang. Oleh manyarakat Kabupaten Rembang, ikan manyung sangat digemari untuk diolah menjadi makanan khas yaitu "kelo mrico ndas manyung". Sedangkan motif Sekar Jagad dipilih karena menjadi motif khas batik lasem, dan motif batik ini sendiri mengandung makna isi alam semesta. Hal tersebut melambangkangkan Kabupaten Rembang yang memiliki kekayaan baik hasil alam, budaya, dan sejarah. Selain itu hasil fotografi dari tempat-tempat wisata Kabupaten Rembang digunakan untuk memberikan gambaran pada audience bagaimana suasana wisata yang ada di Kabupaten Rembang.

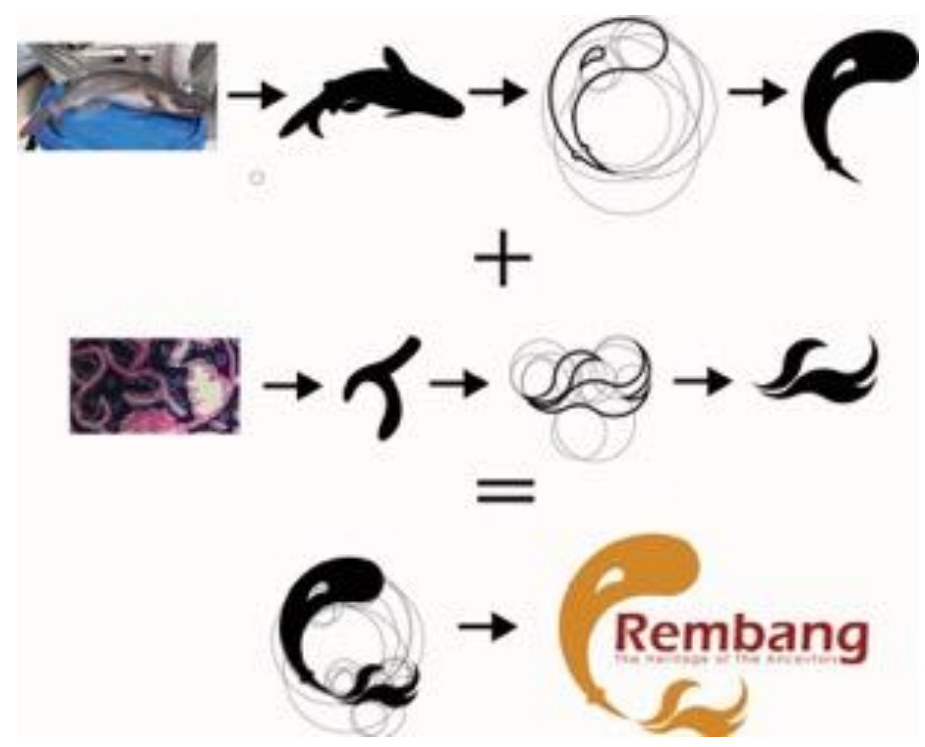

Gambar 4. Sketsa Proses Rancangan Visual Logo

[Sumber: Yusantiar 2017:117]

\section{Identitas Visual}

Pada perancangan logo terdapat logogram serta logotype. Logogram dibuat dengan menyertakan unsur Batik Lasem yaitu Motif Sekar Jagad yang dikombinasikan dengan hasil penyederhanaan dari visual ikan manyung. Dalam perancangan logo pariwisata 
Kabupaten Rembang digunakan tipografi Eras Demi ITC dengan jenis regular. Penggunaan font tesebut bertujuan untuk mengimbangi logogram yang dominan namun tetap mengandung unsur estetik.

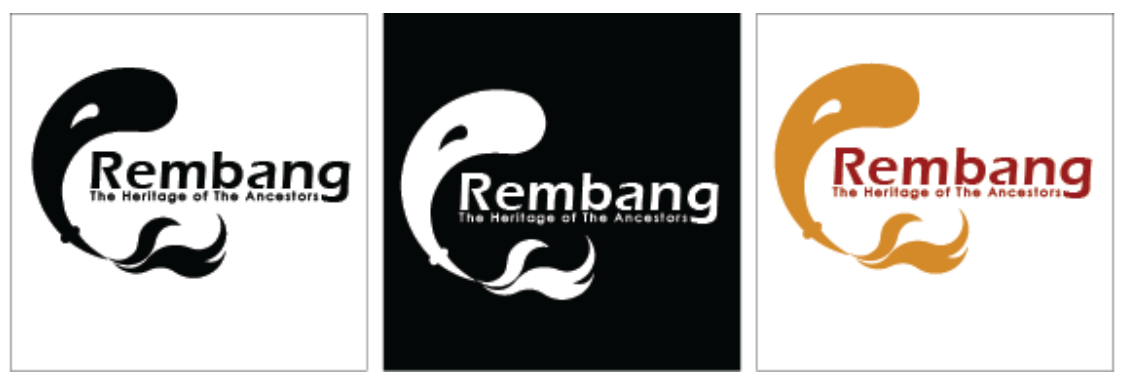

Gambar 5. Hasil Perancangan Logo Pariwisata Kabupaten Rembang

[Sumber: Yusantiar, 2017:121]

Selain logo utama Pariwisata Kabupaten Rembang, juga dilakukan perancangan terhadap ikon dari setiap tempat wisata. Ikon tersebut mengandung logogram ditambah dengan visualisasi sederhana yang menggambarkan lokasi wisata. Rancangan ini akan ditempatkan pada lokasi-lokasi wisata di Kabupaten Rembang dan pada media-media promosi.

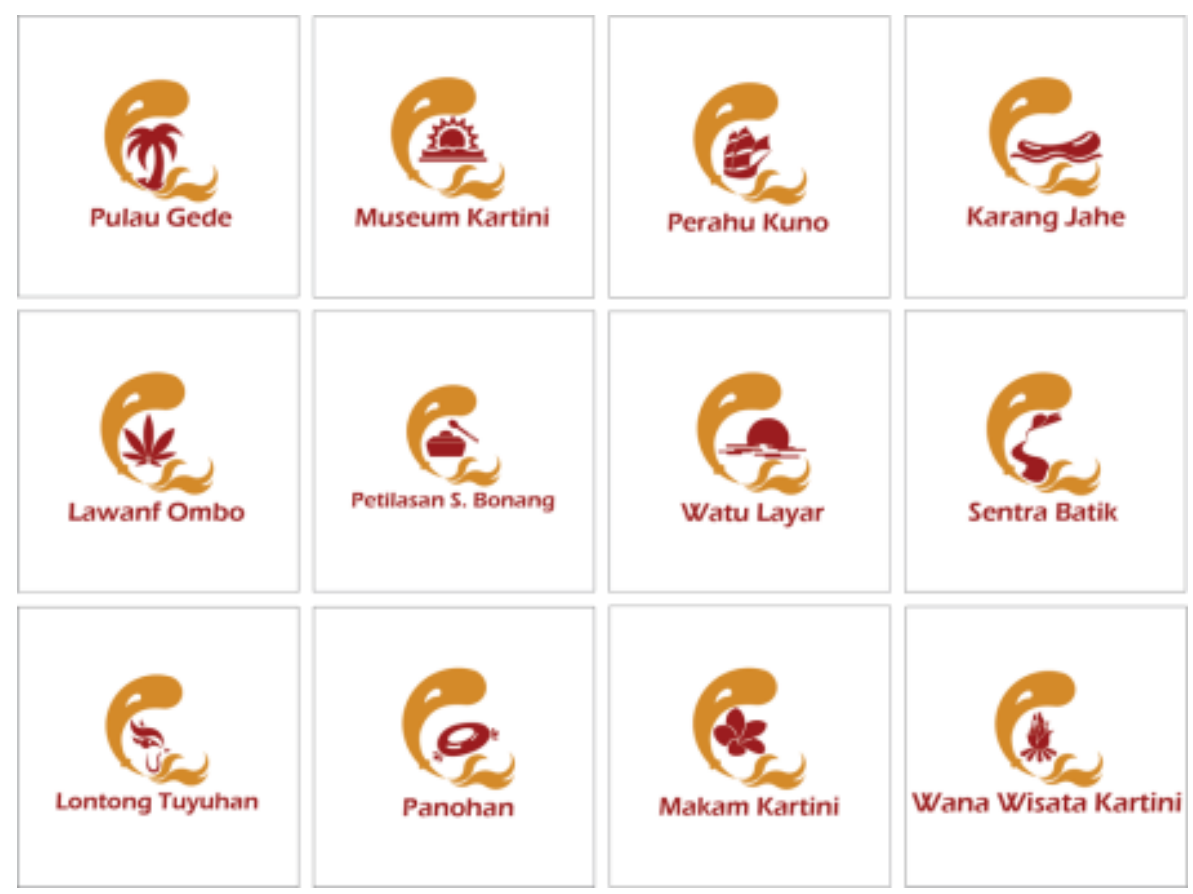

Gambar 6. Hasil Perancangan Icon Lokasi Wisata

[Sumber : Yusantiar, 2017;122]

\section{Konsep Kreatif}

Untuk menarik minat target audiens mengunjungi Kabupaten Rembang, digunakan penawaran paket wisata lengkap, dengan harga terjangkau. Dalam paket wisata tersebut target audiens dapat menikmati keindahan alam serta tradisi dari masyarakat 
Kabupaten Rembang. Sehingga dengan berkunjung ke Kabupaten Rembang, target audiens tidak hanya memperoleh kesenangan berlibur bersama keluarga namun juga dapat merasakan keaslian alam, budaya serta hemat pengeluaran untuk berlibur. Untuk perancangan visual, unsur-unsur khas dari Kabupaten Rembang seperti warna, motif batik, dan hasil alam akan digunakan sebagai elemen pendukung dalam desain untuk menarik perhatian serta menjadikannya sebagai ciri khas Kabupaten Rembang. Sehingga setiap ciri khas tersebut akan lebih mudah diingat oleh target audiens sehingga akan mengingatkan pula pada Kabupaten Rembang.

\section{Konsep Visual}

Dalam sebuah desain membutuhkan jenis font yang mudah di baca dan di pahami. Sehingga informasi yang disampaikan melalui tulisan dapat diterima dan dipahami oleh target audiens tanpa adanya kesalahan dalam memaknai huruf. Cara efektif untuk memunculkan identitas merek adalah dengan memanfaatkan unsur visual yang merangsang penglihatan. Salah satu unsur visual yang dominan adalah warna. Agar warna dapat dengan efektif memperkuat identitas merek, pemilihan warna harus disesuaikan dengan target audiens dan juga asosiasi warna dan produk yang ditawarkan. (Swasty \& Utama, 2017:14) . Warna-warna yang digunakan adalah merah, kuning dan biru, yang melambangkan budaya dan kondisi alam dari Kabupaten Rembang. Warna merah dan kuning dari pengaruh budaya Tionghoa, dan warna biru melambangkan kekayaan laut yang dimiliki oleh kabupaten Rembang. Sedangkan dalam ilustrasi, digunakan elemen-elemen dari Motif Batik Sekar Jagad yang menjadi salah satu motif khas Batik Lasem.

\subsection{Konsep Media Promosi}

Strategi promosi wisata Kabupaten Rembang akan dilaksanakan dalam kurun waktu satu tahun dengan menggunakan metode AISAS seperti tabel dibawah ini.

Tabel 3. Perencanaan Media

[Sumber: Yusantiar, 2017:119]

\begin{tabular}{|c|c|c|c|}
\hline Tahapan & Media & Lokasi & Tujuan \\
\hline \multirow[t]{4}{*}{ Attention } & Billboard & $\begin{array}{l}\text { - Perbatasan } \\
\text { memasuki Kab. } \\
\text { Rembang } \\
\text { - Alun-alun } \\
\text { Rembang }\end{array}$ & \multirow{4}{*}{$\begin{array}{l}\text { Untuk menarik } \\
\text { perhatian audiens pada } \\
\text { tempat wisata Kab. } \\
\text { Rembang }\end{array}$} \\
\hline & Iklan Bus & $\begin{array}{l}\text { Kaca Belakang } \\
\text { Bus Antar Kota } \\
\text { Antar Provinsi }\end{array}$ & \\
\hline & Signage & Lokasi Wisata & \\
\hline & Media Sosial & $\begin{array}{l}\text { Instagram } \\
\text { Facebook }\end{array}$ & \\
\hline
\end{tabular}




\begin{tabular}{|c|c|c|c|}
\hline \multirow[t]{2}{*}{ Interest } & Media Sosial & $\begin{array}{l}\text { Instagram } \\
\text { Facebook }\end{array}$ & \multirow[b]{2}{*}{$\begin{array}{l}\text { Membuat audiens ingin } \\
\text { mengunjungi Kab. } \\
\text { Rembang }\end{array}$} \\
\hline & X Banner & $\begin{array}{l}\text { - Show Room } \\
\text { Batik Lasem } \\
\text { - Pusat Informasi } \\
\text { Wisata Kab. } \\
\text { Rembang }\end{array}$ & \\
\hline \multirow[t]{3}{*}{ Search } & Guide Book & $\begin{array}{l}\text { - Pusat informasi } \\
\text { wisata Kab. } \\
\text { Rembang }\end{array}$ & \multirow{3}{*}{$\begin{array}{l}\text { Memberikan informasi } \\
\text { secara rinci kepada } \\
\text { audiens }\end{array}$} \\
\hline & Website & Online & \\
\hline & Media Sosial & $\begin{array}{l}\text { Facebook, } \\
\text { Instagram }\end{array}$ & \\
\hline \multirow[t]{2}{*}{ Action } & Website & Online & \multirow[b]{2}{*}{$\begin{array}{l}\text { - Pembelian paket } \\
\text { wisata } \\
\text { - Pemesanan hotel } \\
\text { - Penanda pengunjung } \\
\text { lokasi wisata, dan } \\
\text { mempermudah } \\
\text { penghitungan jumlah } \\
\text { pengunjung }\end{array}$} \\
\hline & Tiket & Lokasi wisata & \\
\hline \multirow[t]{2}{*}{ Share } & Media Sosial & $\begin{array}{l}\text { Facebook dan } \\
\text { Instagram }\end{array}$ & \multirow{2}{*}{$\begin{array}{l}\text { - Sebagai tanda telah } \\
\text { berkunjung ke Kab. } \\
\text { Rembang } \\
\text {-Untuk mempromosikan } \\
\text { wisata Kab. Rembang } \\
\text { kepada orang terdekat }\end{array}$} \\
\hline & Merchandise & $\begin{array}{l}\text {-Lokasi wisata } \\
\text { Pusat oleh-oleh }\end{array}$ & \\
\hline
\end{tabular}

\section{Rincian Media Promosi}

1) Peta Wisata. Perancangan peta wisata bertujuan untuk memudahkan pengunjung dalam menemukan lokasi wisata serta mengatur perjalanan yang sesuai dengan waktu yang dimiliki. Peta wisata ini dapat dilihat di dalam guide book serta website dari wisata Kabupaten Rembang. 2) Website. Website akan memudahkan pengunjung untuk memperoleh segala informasi yang diperlukan ketika berlibur ke Kabupaten Rembang. Didalamnya tidak hanya informasi tentang wisata yang dapat di temukan, namun juga informasi penginapan, paket wisata, acara tahunan dan makananmakanan khas yang terdapat di Kabupaten Rembang. Domain dari website ini adalah www.rembang.tourism.com. 


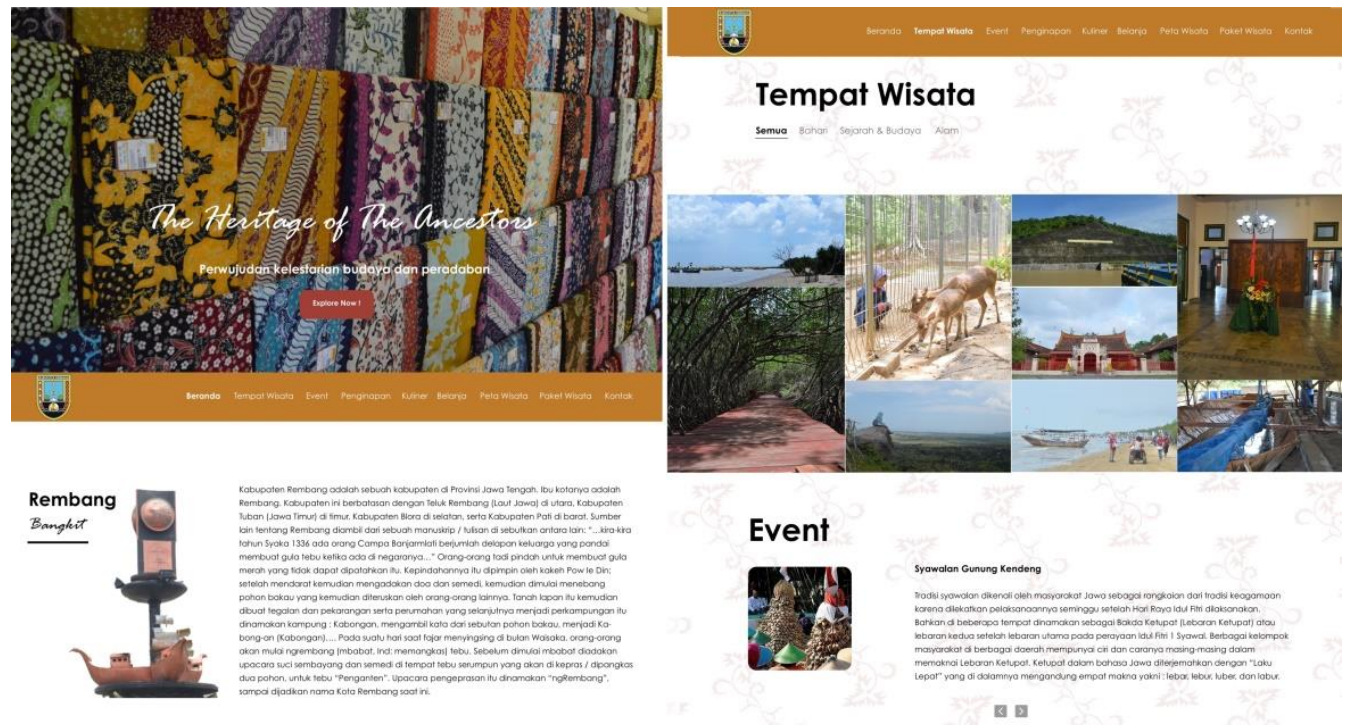

Gambar 7. Perancangan Website

[Sumber: Yusantiar, 2017;122]

3) Media Sosial. Sosial media digunakan untuk mencapai target audiens secara lebih luas. Dalam sosial media dapat di temukan informasi-informasi mengenai tempat wisata, makanan khas serta acara yang akan dan telah diadakan di Kabupaten Rembang. Nama yang digunakan dalam facebook adalah Rembang Tourism, sedangkan pada Instagram adalah rembang_tourism. Disini pengunjung juga dapat berpartisipasi dalam mempromosikan wisata Kabupaten Rembang, dengan cara mengunggah foto lokasi wisata pada akun sosial media masing-masing kemudian menandai akun sosial media wisata Kabupaten Rembang serta menyertakan \#rembangtourism dan \#ayowisatakerembang pada kolom caption. Admin media sosial dari wisata kabupaten Rembang akan memilih yang foto-foto untuk dibagikan atau repost di akun sosial media Wisata Kabupaten Rembang. 4) Tiket. Tiket digunakan sebagai tanda masuk pengunjung pada lokasi wisata Kabupaten Rembang. Selain itu tiket juga berfungsi untuk memudahkan pengelola dalam menghitung jumlah pengunjung. 5) Guide Book. Dalam guide book terdapat informasi secara detail mengenai lokasi-lokasi wisata yang terdapat di Kabupaten Rembang. Buku panduan wisata ini dapat diperoleh pengunjung di pusat informasi wisata yang berada di kawasan Dinas Kebudayaan, Pariwisata, Pemuda dan Olahraga Kabupaten Rembang yang beralamat di Jalan Gatot Subroto no 8, Kutoharjo Rembang. Guide book memiliki ukuran A5 atau $21 \times 14,85 \mathrm{~cm}$ dengan posisi portrait. Ukuran tersebut dipilih dengan tujuan untuk memudahkan audiens dalam membawa guide book selama perjalanan. 6) Iklan Bus. Iklan bus dipilih karena bus menjadi sarana transportasi utama untuk menuju Kabupaten Rembang. Sehingga melalui iklan bus, tidak hanya mempromosikan wisata Kabupaten Rembang, melainkan juga menginformasikan bahwa untuk menuju Kabupaten Rembang dapat menggunakan transportasi tersebut. 7) X-Banner. X-banner betujuan untuk membuat orang tertarik untuk dating dan berwisata ke Kabupaten Rembang. X-Banner akan ditempatkan pada pusat informasi wisata dan di stand pameran Kabupaten Rembang seperti pada acara ina craft. 8) Billboard. Dalam billboard, calon pengunjung ditarik 
dengan foto keluarga yang tengah berlibur dan bermain dengan gembira sehingga target audiens berminat untuk mampir dan berwisata ke Kabupaten Rembang. 9) Poster. Poster akan digunakan untuk mempromosikan acara-acara yang berkaitan dengan wisata Kabupaten Rembang. Poster ini akan di muat pada website, sosial media, dan ruang public seperti papan informasi kota yang berada di alun-alun Kabupaten Rembang.

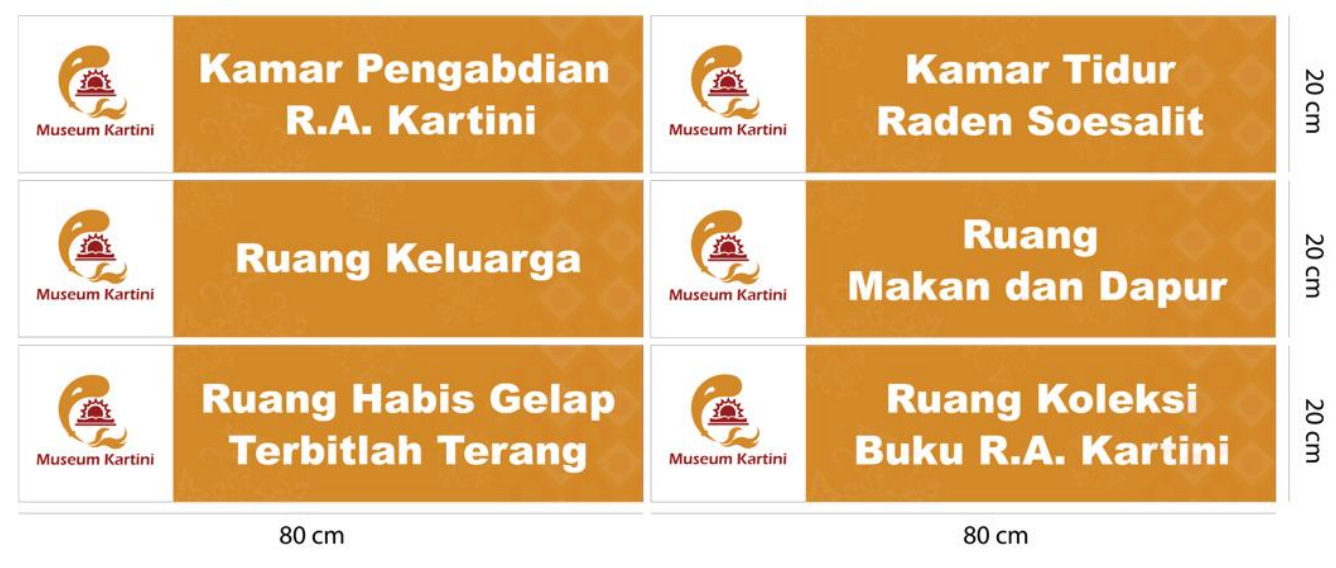

Gambar 8. Perancangan Signage dalam Ruangan

[Sumber: Yusantiar, 2017;136]

10) Signage. Terdiri atas dua bagian, yaitu untuk dalam dan luar ruangan. Untuk signage dalam ruangan, akan ditempatkan pada lokasi wisata yang bersifat indoor ataupun memiliki ruang-ruang, seperti di Museum Kartini. Sedangkan signage luar ruang digunakan untuk menunjukkan lokasi setiap lokasi wisata Kabupaten Rembang, sehingga akan ditempatkan pada setiap pintuk masuk lokasi wisata. 11) Merchandise. Gantungan kunci terbuat dari bahan kayu, hal tersebut berdasarkan pada Kabupaten Rembang yang menjadi salah satu penghasil kayu jati. Sedangkang kipas terbuat dari kain bermotif batik lasem dan terdapat logo wisata Kabupaten Rembang. Kipas dibuat karena udara Kabupaten Rembang cukup panas berkisar antara 29-32 ${ }^{\circ} \mathrm{C}$. Sedangkan tumbler dibuat agar pengunjung dapat membawa minum sendiri, sehingga tidak perlu membeli pada setiap tempat wisata. Hal ini untuk mengurangi sampah yang bias saja mengotori lokasi wisata karena pembuangan sampah yang sembarangan.

\section{KESIMPULAN}

Dalam proses penelitian ini, Wisata Kabupaten Rembang memiliki permasalahan pada logo dan media promosi. Pada logo lama wisata Kabupaten Rembang menggunakan foto hitam putih RA Kartini dengan bingkai lonjong. Media promosi yang telah ada sebelumnya tidak memiliki keseragaman dalam penggunaan elemen visual, seperti warna dan tipografi, sehingga diperlukan perancangan ulang logo dan promosi wisata Kabupaten Rembang, untuk meningkatkan pengetahuan masyarakat luas tentang wisata Kabupaten Rembang. Perancangan memuat media unsur-unsur visual khas dari Kabupaten Rembang, seperti warna dan motif batik untuk menggambarkan Kabupaten Rembang. 


\section{UCAPAN TERIMAKASIH}

Bapak Muhammad Jamaludin, SE., Seksi Informasi dan Promosi Pariwisata, Dinas Kebudayaan, Pariwisata, Pemuda dan Olahraga Kabupaten Rembang

\section{DAFTAR PUSTAKA}

Ardhi, Y. 2013. Merancang Media Promosi yang Unik dan Menarik. Yogyakarta: TAKA Publisher.

Morrisan. 2010. Periklanan : Komunikasi Pemasaran Terpadu. Jakarta: Kencana Prenadamedia Group.

Pariwisata, K. 2017, Januari 3. Data Kunjungan Wisatawan Mancanegara Bulanan Tahun 2016. diakses di kemenpar.go.id: http://www.kemenpar.go.id/asp/detil.asp?c=110\&id=3139 (28 Januari 2017, 18:40)

Soewardikoen, D. W. 2013. Metodologi Penelitian Visual. Bandung: Dinamika Komunika.

Soewardikoen, D. W. 2015. Visualisasi Iklan Indonesia Era 1950-1957 Edisi 2. Yogyakarta: Calpulis.

Swasty, W., \& Utama, J. 2017. WARNA SEBAGAI IDENTITAS MEREK PADA WEBSITE. ANDHARUPA: Jurnal Desain Komunikasi Visual \& Multimedia, 3(1), 1-16.

Swasty, W. 2016. Branding. Bandung: PT Remaja Rosdakarya.

Wibowo, I. T. 2013. Belajar Desain Grafis. Yogyakarta: Buku Pintar.

Yusantiar, R. 2017. Perancangan Logo Sebagai Identitas Visual dan Promosi Pariwisata Kabupaten Rembang. Laporan Tugas Akhir. Bandung: Openlibrary Telkom University 